\title{
17. Participatory evaluation in transport planning: the application of Multi-Actor Multi-Criteria Analysis in co-creation to solve mobility problems in Brussels
}

\author{
Jesse Pappers, Imre Keserü and Cathy \\ Macharis
}

\subsection{INTRODUCTION}

Transport is the eighth leading cause of death globally, with 1.35 million deaths and 50 million injuries each year (World Health Organization, 2018). Proposed solutions to transport problems are usually solved by transport planners who often approach problems with what Healey (1992) calls narrow scientific rationalism in which economic concerns trump social and environmental ones. In this type of planning, citizens often have no say in decisions that have a direct impact on their lives. Instead, it is politicians that take decisions based on plans drawn by transport planners. This top-down, expert-led approach to transport planning is being challenged by public participation (Booth and Richardson, 2001). To what extent the public can participate, is indicated by the level of participation. Arnstein's (1969) ladder of participation ranges from manipulating the public to accept a solution, to allowing citizens to take decisions. Public participation in transport planning, however, is often limited to informing and consulting (Gil et al., 2011).

Citizens should be at the centre of human scale cities. In recent years, co-creation has been coined as an umbrella term for the higher levels of participation in which citizens have decision-making power. However, transport-related co-creation processes often lack a participatory element in the evaluation of the co-created outcome, that is, when possible solutions have been identified but a decision needs to be made on which solution(s) should be implemented (Pappers et al., 2020). This chapter seeks to address this research gap by proposing the involvement of citizens and stakeholders in the 
ex-ante participatory evaluation of co-designed solutions using Multi-Actor Multi-Criteria Analysis (MAMCA). The proposed integration of co-creation and participatory evaluation is demonstrated by evaluating co-designed solutions to improve traffic safety in Brussels, Belgium. This chapter addresses the following research questions:

1. How can participatory evaluation using MAMCA be applied in a co-creation process?

2. What are the benefits and limitations of participatory evaluation using MAMCA in a co-creation process?

\subsection{LITERATURE REVIEW}

Participation of the public in a planning process is a double-edged sword. Public participation is said to increase the legitimacy of and support for decisions, lead to more innovative solutions by drawing from citizens' knowledge, and increase citizens' knowledge and interpersonal skills (Holden, 2011; Larson and Lach, 2008; Schroeter et al., 2016). However, public participation can also slow down the decision-making process, and decrease the legitimacy of a decision when participation is limited to certain groups (Holden, 2011; Transplus, 2003). Furthermore, different levels of participation have different levels of involvement from the public, ranging from manipulation of people to giving people full managerial control (Arnstein, 1969). Co-creation can be seen as a form of public participation that is situated on the highest rungs of the ladder of participation, and focuses on creativity and innovation (Pappers et al., 2020).

Participatory planning is defined as 'the involvement of any individual, group or community' in the planning process (Smith, 1973, p. 279). Involving citizens in the planning process can provide planners with detailed and local information and can increase citizens' competences. Whereas the legitimacy of a planning process may increase by including groups with conflicting points of view, this can also reduce the adaptiveness of the planning process (Smith, 1973). Furthermore, if all points of view are taken into account, the outcome of any participation process will necessarily be the middle ground. This 'tyranny of the median' will prevent radical solutions that are necessary to tackle problems, because they are not supported by the majority (Kaza, 2006). However, Stagl (2006) shows how this 'tyranny' can be overcome when citizens change their point of view during the participation process.

Evaluation in transport planning is often carried out using formal evaluation methods such as cost-benefit analysis (CBA) and multi-criteria analysis (MCA). The outcomes of these methods are used to inform decision-makers of the impacts of different alternative solutions to a problem. CBA shows the 
costs and benefits of alternative solutions to all members of society and allows for a ranking of the solutions based on the costs and benefits (Boardman et al., 2018). However, the evaluation method is heavily criticized for its reliance on economically quantifiable measures and its unsuitability for complex planning problems. MCA uses quantitative and qualitative criteria to evaluate alternative solutions and allows for a ranking of the solutions based on their impacts on the selected criteria. The priorities in MCA depend on the context in which it is applied (Te Boveldt, 2019). MCA is increasingly applied to evaluate the impacts of transport projects (Macharis and Bernardini, 2015).

Evaluation is participatory if there is active engagement of multiple stakeholders, including citizens (Mathie and Greene, 1997). Whereas evaluation using traditional methods such as CBA claims to be objective by using quantified methods, participatory evaluation cannot be neutral as the evaluator's interventions cannot be value free (Plottu and Plottu, 2009). For example, when making evaluation participatory, issues arise such as how to correctly identify stakeholders and how to correctly obtain preferences from them (Harrison and Qureshi, 2000). Furthermore, when there are too many stakeholders participating in an evaluation, the diversity of opinions may make reaching a consensus impossible (Mathie and Greene, 1997).

There are different degrees of participatory evaluation using MCA, depending on whether an analyst or the stakeholders themselves are responsible for the generation of alternative solutions, the priorities (that is, criteria and weights) against which alternatives are evaluated, and evaluating the impact of the alternative solutions on the stakeholders' criteria (Dean, 2018). A rather low-key form of participatory evaluation is to ask citizens and stakeholders to rank alternative solutions, as has been done for energy policy in the United Kingdom (Stagl, 2006) and sustainable mobility policies in Italy (Marletto and Mameli, 2012). Muñuzuri et al. (2016) and Macharis et al. (2010) go beyond asking stakeholders to rank alternative solutions by looking at the impact of these solutions on stakeholders' objectives and ranking the alternative solutions on this impact. In the participatory MCA to assess potential rail investments in England conducted by Dean and Hickman (2018), stakeholders were also responsible for the evaluation of the impact of the alternative solutions on their own criteria.

\subsection{METHOD: MAMCA}

Multi-Actor Multi-Criteria Analysis (MAMCA) is used to analyse how the priorities of different stakeholders are impacted upon by alternative solutions that aim to improve the current situation. Knowing how different stakeholders are affected by alternative solutions gives an indication of the level of support from each stakeholder that can be expected for each alternative solution (Macharis 
and Bernardini, 2015). The aim of MAMCA is thus to provide insight into the priorities of different stakeholders and not to 'simply' select and implement the alternative solution with the highest ranking (Macharis et al., 2012).

MAMCA consists of seven steps. The methodology starts with the identification of the problem and the definition of the alternative solutions (step 1). This is followed by the identification of the relevant stakeholders and their key objectives (step 2). The objective of each stakeholder is translated into criteria and weights, that is, the relative importance a stakeholder attaches to a criterion (step 3). In order to measure the impact of alternative solutions on a stakeholder's objective, one or more indicators is constructed for each criterion as well as a measurement method for each indicator (step 4). Using the criteria and indicators, an MCA is performed for each stakeholder in order to find out the impact of the alternative solutions on the stakeholder's objective (step 5). The outcome of each stakeholder's MCA is combined by visualizing how each stakeholder is affected by each alternative solution (step 6). This step not only shows a ranking of the alternative solutions based on their impact on the stakeholder's criteria, but also indicates which stakeholders and which criteria are critical in order to come to a consensus on which alternative solution(s) will be implemented. The final step in the process is the implementation of the chosen alternative solution (step 7) (Macharis, 2007).

The novel approach proposed in this chapter is the link between the co-creation process and participatory evaluation using MAMCA. First, the alternative solutions are co-designed by citizens. In previous evaluations using participatory MCAs such as MAMCA, the alternative solutions were predefined by the analysts guiding the evaluation (Almeida, 2019; Macharis et al., 2009; Turcksin et al., 2011) or suggested by stakeholders (Bana E Costa, 2001; Macharis et al., 2010; Macharis and Januarius, 2010; Verlinde and Macharis, 2016). Second, although citizens' ideas have been collected and sometimes implemented in other transport-related co-creation projects, there was no formal ex ante evaluation of the alternative solutions (Pappers et al., 2020).

\subsection{APPLICATION OF MAMCA IN A CO-CREATION PROCESS}

\subsubsection{Participatory Evaluation using MAMCA}

The participatory evaluation using MAMCA took place in a living lab on traffic safety in Brussels. The explicit involvement of citizens and stakeholders was at the core of the co-creation approach used in this living lab. Awareness of the living lab was raised via posts on the project website and social media, the network of the local non-governmental organization (NGO) tasked with 
the organization of the living lab, and the newsletter of the municipality in which the living lab was located.

Citizens identified traffic safety as one of the most urgent problems in the municipality, and set up a data collection campaign during three workshops. The data collection campaign included a survey about the mobility preferences of residents, a mobile application through which citizens could indicate places where there are traffic safety hotspots, and participatory data collection to count traffic and measure the speed of cars. The traffic count showed that traffic in the neighbourhood is mostly small vehicles such as passenger cars as well as pedestrians; large vehicles and cyclists are only a minority. During the speed measurements, 33 per cent of all measured vehicles $(n=618)$ were driving over the speed limit of $30 \mathrm{~km} / \mathrm{h}$.

Citizens and stakeholders could submit ideas (that is, alternative solutions) to improve traffic safety in the neighbourhood via an online platform (brussels .looperproject.eu/idea) as well as during the previously mentioned workshops. The 43 submitted alternative solutions were then narrowed down to five by citizens during a fourth workshop. The remainder of this section will discuss the five selected co-designed solutions and their evaluation following the steps of MAMCA.

\subsubsection{Step 1: Definition of Alternatives}

The alternative solutions that improve traffic safety were co-designed by citizens. The following co-designed alternative solutions were selected during the fourth workshop:

1. Improve signalization at a dangerous intersection.

2. Indicate alternative cycling routes to avoid a busy high street.

3. Set up an awareness campaign to inform road users of children in the streets.

4. Reduce road width using temporary installations.

5. Speed meters that visualize the speed of road users using smileys.

Besides these five co-designed alternative solutions, a sixth alternative called 'no intervention' was added. This was to see the impact of maintaining the current situation on the stakeholders' objectives.

\subsubsection{Step 2: Stakeholder Analysis}

The relevant stakeholders to be included in the evaluation of the co-designed alternative solutions were identified by citizens during the workshops. During interviews held by the researchers with the identified stakeholders, the inter- 
viewees were asked which other stakeholders should be included in the evaluation process. This led to the identification of the following stakeholder groups: citizens; the Ministry of Mobility of the Brussels Capital Region; the cycling NGO GRACQ; the Brussels public transport operator STIB; the Mobility Department of the municipality of Schaerbeek; and the police. The police were excluded from the evaluation because they could not obtain permission in time to participate.

\subsubsection{Step 3: Definition of Criteria and Weights}

Each stakeholder group defined their own criteria and weights (that is, the level of importance a stakeholder group attaches to a criterion). This was done during interviews with stakeholder representatives. Each interview with a stakeholder representative started with an introduction of the living lab, followed by an overview of the five co-designed alternative solutions. The stakeholder representative could then share their thoughts on the solutions as well as traffic safety in general. The interviewer - a researcher of the living lab - then compiled a list of criteria and verified these with the stakeholder representative. Lastly, pairwise comparison was used by the stakeholder representative to attach weights to the selected criteria. An overview of the criteria and weights of each stakeholder group can be found in Table 17.1.

A different approach was necessary to define the criteria and weights for citizens, because there was no representative identified for this stakeholder group. Citizens' criteria had been identified during discussions in the four co-creation workshops of the living lab, by talking to citizens on the street, and through a neighbourhood-wide survey on the citizens' priorities regarding traffic safety. Due to the voluntary nature of participation in the living lab, the sample of citizens that participated in the MAMCA is not representative of the wider population. A survey showed that participants were mostly female, highly educated and used sustainable modes of transport (that is, bicycle and public transport) most often.

The 123 respondents of the neighbourhood-wide survey mentioned the following criteria most often: air quality, traffic safety, cycling infrastructure, noise pollution, availability of parking places for cars, accessibility of public transport stops. In a second survey, 36 citizens attached weights to these six criteria using pairwise comparison. The average weighting of the citizens responses was calculated using Goepel's (2018) tool that uses the analytic hierarchy process (AHP) to calculate average weights of multiple respondents within one stakeholder group. Viewing citizens as one stakeholder group does obscure the different viewpoints within this group, however. 
Table 17.1 The criteria, indicators and weights per stakeholder group

\begin{tabular}{|c|c|c|c|}
\hline Stakeholder group & Criteria & Indicator(s) & Weight \\
\hline \multirow[t]{10}{*}{ Citizens } & Traffic safety & Number of accidents & 2400 \\
\hline & & Perception of safety & $34.0 \%$ \\
\hline & $\begin{array}{l}\text { Availability of cycling } \\
\text { infrastructure }\end{array}$ & $\begin{array}{l}\text { Availability of separated cycling lanes and } \\
\text { bike parking }\end{array}$ & $22.9 \%$ \\
\hline & Air quality & PM2.5 emissions & $131 \%$ \\
\hline & & $\mathrm{NO}_{\mathrm{x}}$ emissions & \\
\hline & Noise & Perception of transport noise & \\
\hline & & Exposure to transport noise & $11.0 \%$ \\
\hline & & Produced noise & \\
\hline & $\begin{array}{l}\text { Availability of car } \\
\text { parking }\end{array}$ & Availability of parking spaces for cars & $3.5 \%$ \\
\hline & $\begin{array}{l}\text { Accessibility of public } \\
\text { transport stops }\end{array}$ & $\begin{array}{l}\text { The average distance to a public transport } \\
\text { stop }\end{array}$ & $15.5 \%$ \\
\hline \multirow[t]{5}{*}{$\begin{array}{l}\text { Brussels public } \\
\text { transport operator }\end{array}$} & $\begin{array}{l}\text { Reliability of public } \\
\text { transport system }\end{array}$ & $\begin{array}{l}\text { Percentage of metros, trams and buses that } \\
\text { are on time }\end{array}$ & $50.2 \%$ \\
\hline & Traffic safety & Number of accidents & $23.7 \%$ \\
\hline & & Perception of safety & \\
\hline & $\begin{array}{l}\text { Accessibility for people } \\
\text { with special needs }\end{array}$ & Level of fully accessible services & $14.6 \%$ \\
\hline & $\begin{array}{l}\text { Public funding of } \\
\text { transport }\end{array}$ & $\begin{array}{l}\text { Level of transport subsidies for investments } \\
\text { Level of transport subsidies for operating } \\
\text { costs }\end{array}$ & $11.5 \%$ \\
\hline \multirow{6}{*}{$\begin{array}{l}\text { Brussels Ministry of } \\
\text { Mobility }\end{array}$} & Liveability & Walkability and pedestrian friendliness & $37.8 \%$ \\
\hline & & Quality of urban space & \\
\hline & Traffic safety & Number of accidents & $22.7 \%$ \\
\hline & & Perception of safety & \\
\hline & $\begin{array}{l}\text { Accessibility for people } \\
\text { with special needs }\end{array}$ & Level of fully accessible services & $21.4 \%$ \\
\hline & Circulation & $\begin{array}{l}\text { Flow of traffic for all road users; in order } \\
\text { of importance: pedestrians, cyclists, public } \\
\text { transport and private transport }\end{array}$ & $18.1 \%$ \\
\hline
\end{tabular}




\begin{tabular}{|c|c|c|c|}
\hline Stakeholder group & Criteria & Indicator(s) & Weight \\
\hline \multirow{8}{*}{$\begin{array}{l}\text { Schaerbeek } \\
\text { municipality }\end{array}$} & Traffic safety & Number of accidents & $63.5 \%$ \\
\hline & & Perception of safety & \\
\hline & $\begin{array}{l}\text { Accessibility for people } \\
\text { with special needs }\end{array}$ & Level of fully accessible services & $17.0 \%$ \\
\hline & Air quality & PM2.5 emissions & $15.4 \%$ \\
\hline & & $\mathrm{NO}_{\mathrm{x}}$ emissions & \\
\hline & Noise & Perception of transport noise & $4.1 \%$ \\
\hline & & Exposure to transport noise & \\
\hline & & Produced noise & \\
\hline \multirow[t]{9}{*}{ Cycling NGO } & Quality of cycling & Infrastructure such as separated cycling lanes & $45.7 \%$ \\
\hline & infrastructure & and bike parking & \\
\hline & Traffic safety & Number of accidents & $38.3 \%$ \\
\hline & & Perception of safety & \\
\hline & Air quality & PM2.5 emissions & $10.8 \%$ \\
\hline & & $\mathrm{NO}_{\mathrm{x}}$ emissions & \\
\hline & Cost-effectiveness & Investment costs & $5.2 \%$ \\
\hline & & Operating costs & \\
\hline & & Revenues & \\
\hline
\end{tabular}

Note: NOx: nitrogen oxides; PM2.5: particulate matter 2.5.

\subsubsection{Step 4: Criteria, Indicators and Measurement Methods}

Table 17.1 gives an overview of the criteria and indicators per stakeholder group. All stakeholder groups identified traffic safety as a criterion, and four out of five stakeholder groups mentioned air quality. The three institutional stakeholders - municipal and regional governments and the regional public transport operator - also mentioned accessibility for people with special needs.

\subsubsection{Step 5: Overall Analysis and Ranking}

This step determines the impact of the co-designed solutions on the stakeholders' criteria. Since MAMCA is done ex ante, the impact of a co-designed solution on a criterion was predicted by experts who based their judgement on their knowledge. Moreover, modelling or measuring the change in the indicators was not possible in this case. The experts who performed the evaluation were traffic safety experts of the Belgian Road Research Centre, mobility researchers at the Vrije Universiteit Brussel, and employees of the Brussels urban sustainability NGO BRAL.

The Preference Ranking Organisation Method for Enrichment Evaluation (PROMETHEE) developed by Brans et al. (1986) was used to evaluate the impact of a co-designed solution on a criterion. A seven-point impact scale 
ranging from very negative to very positive was applied. If a solution did not impact a criterion, the fourth point on the scale was chosen, that is, 'neutral'. Then, the evaluation score of each alternative for each stakeholder was calculated using the weighted sum method. This is done by determining the overall score of an alternative $(V)$ by calculating the sum of all performance scores $(v)$ on the criteria $\left({ }_{i}\right)$ multiplied by their respective weights $(w)$ (Dodgson et al., 2009):

$$
V(a)=\sum_{i=1}^{n} w_{i} v_{i}(a)
$$

\subsubsection{Step 6: Results}

The results of the evaluation show that there was consensus across the stakeholder groups in terms of their ranking of the proposed alternative solutions. Improving the signalization at the intersection had the highest evaluation score for all stakeholder groups; that is, of all five co-designed solutions it would have the most positive impact on the criteria of all stakeholders. This solution is followed in ranking by the awareness campaign for the presence of children in the streets and the narrowing of the streets. The speed measurements ranked lower, and the alternative cycling routes had the lowest ranking. Because all alternative solutions rank higher than the 'no intervention' scenario, resistance from the different stakeholder groups towards implementing the co-designed solutions was therefore not expected. Figure 17.1 visualizes the ranking of the different alternative solutions. The $\mathrm{x}$-axis shows the stakeholder groups and the $y$-axis shows the evaluation score between -1 and 1 (that is, the impact an alternative has on the stakeholder's criteria).

\subsubsection{Step 7: Implementation}

Although improving the signalization at an intersection was ranked highest by all stakeholder groups, this alternative solution was not immediately implemented. This decision was taken by citizens at a workshop where the results of the MAMCA were discussed. Instead, consensus was found between stakeholders and citizens to implement the street drawing which MAMCA also found to have a positive impact on stakeholders. This decision was based on the evaluation scores as well as practical considerations: redesigning an intersection is a lengthy and costly process and may not be completed in the short term, that is, before the living lab end. Nevertheless, the municipality started the procedures to redesign the intersection. The implementation of 


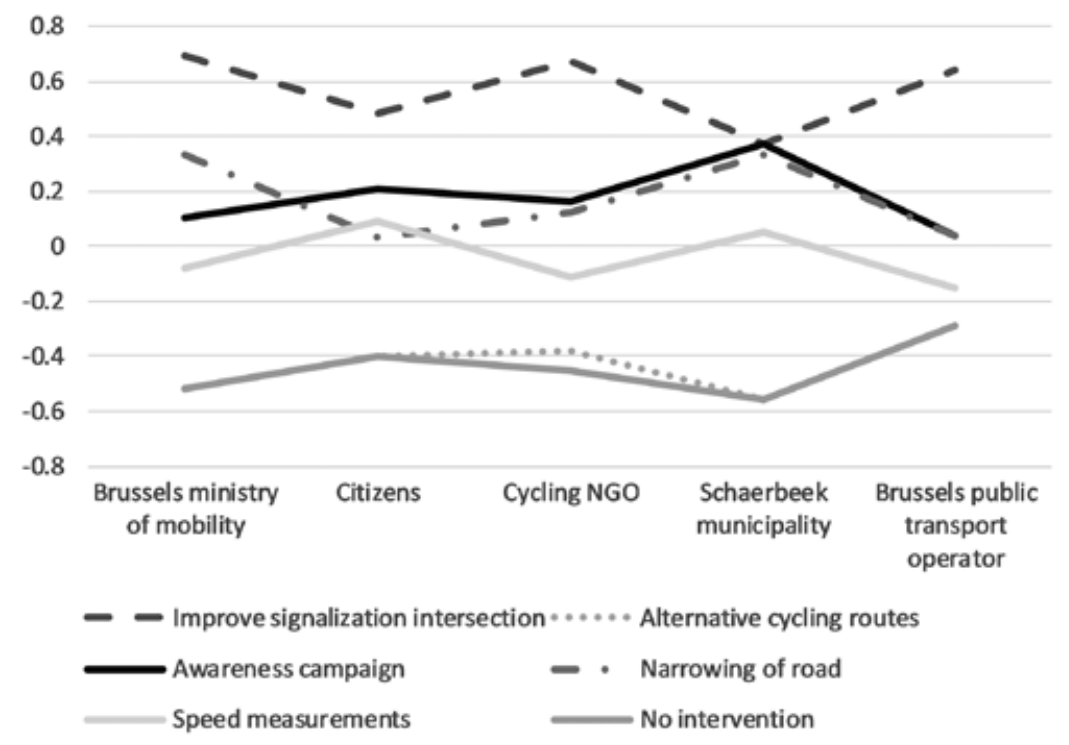

Figure 17.1 The multi-stakeholder ranking visualizing the ranking of the co-designed alternative solutions

the co-designed solution took place during a local NGO's annual street party. A local artist drew the outlines of a traffic safety themed drawing on the intersection in front of the NGO, which children then coloured in. In order to measure the drawing's impact on traffic safety, speed measurements were done one week before and one week after the implementation. No significant impact on the traffic speeds was found, however.

\subsection{DISCUSSION}

Combining participatory evaluation using MAMCA and co-creation was found to influence both the MAMCA process as well as co-creation. When looking at the impacts of co-creation on MAMCA, two advantages were found.

First, co-creation increases the opportunities for citizen engagement in the evaluation of the co-designed solutions. In participatory evaluation, citizens are often included only after the problem as well as the alternative solutions already have been identified. In co-creation, citizens identify the problem, for which they co-design solutions. Citizens are thus involved at an earlier stage, thereby increasing their engagement in the evaluation. 
Second, citizens not only have valuable knowledge of the problems in their neighbourhood and ideas for possible solutions, but also know who is impacted upon by the problem and who will be impacted upon by alternative solutions. This helps in the second step of MAMCA, the identification of stakeholders, and could lead to the inclusion of stakeholders previously not identified. The representativeness of the participating citizens needs to be considered, however. Finding the right communication channels and networks is crucial when wanting to include groups such as the elderly and migrants.

Three disadvantages of applying co-creation to the steps of MAMCA were found. First, co-creation may result in more alternative solutions than can be evaluated. When selecting which solutions will be evaluated, a balance needs to be struck between citizens' wishes, the requirements of MAMCA, and the time and resources available to conduct the evaluation. MAMCA requires the alternative solutions to be significant enough for an impact on criteria to be expected, as well as sufficiently distinct to detect a difference in impact.

Furthermore, in order to make a useful comparison, the solutions should address the same issue at preferably the same location. In Brussels, the evaluators assisted citizens during a workshop in selecting solutions that were comparable and sufficiently distinct. Five out of the 43 proposed solutions were selected for evaluation, which is a manageable number; between four and eight seems to be the norm. Furthermore, citizens were found to be understanding when it was explained why their idea was not selected.

Second, identifying citizens as one stakeholder group does not do justice to their diversity and reduces the representativeness of this stakeholder group. The same can be said about involving stakeholder representatives for other stakeholder groups, who may also not correctly voice the views of the group they are representing. Future research should therefore investigate how citizens can be represented differently, for example by dividing them into distinct stakeholder groups based on their selected criteria and given weights, or by looking at socio-demographic data such as age or car ownership.

Third, the representativeness of the citizens' criteria and weights can be questioned. The selection of criteria was done by more and different citizens than the weighting. Furthermore, only 1 per cent of the neighbourhoods' residents participated in the evaluation. Involving more citizens or using a representative sample of citizens could increase the representativeness of citizens as a stakeholder group, but would also require more resources.

We found five advantages of applying participatory evaluation using MAMCA to co-creation. First, MAMCA extends the 'co' of co-creation to evaluation. This participatory or co-evaluation engages citizens and stakeholders, making them feel more invested in the co-creation process, which in turn can facilitate the implementation of co-designed solutions. This was the case in Brussels, where one co-designed solution has been implemented. 
Second, MAMCA allows each stakeholder to define and attach weights to their criteria. This makes stakeholders reflect on their priorities instead of their perceived preference for certain alternative solutions. When there is no $e x$ ante evaluation of alternative solutions - which is often the case in co-creation projects - the impacts of the co-designed solutions on stakeholders and thus the possible stakeholder support for the co-designed solutions is unknown. This lack of evaluation could reduce the support for the implementation of solutions due to a (perceived) lack of stakeholder support or conflicts with stakeholders' interests. For example, the municipality and the public transport operator perceived the improvement of the signalization at an intersection to be a controversial solution, because they believed other stakeholders would be negatively impacted upon. However, this solution turned out to have the highest level of stakeholder support.

Third, the consensus-making step of MAMCA intertwines with the decision-making in the co-creation process about the solution(s) to be implemented. The outcome of MAMCA is a ranking of alternatives based on their evaluation scores. Visualizing this multi-stakeholder ranking in a graph (see Figure 17.1) helps citizens and stakeholders to understand each other's preferences, can be used as input for discussion in the co-creation process, and helps to identify the solution(s) with the highest level of support from stakeholders. Therefore, the rankings provided by the MAMCA are not to be considered as the ultimate prioritization of the solutions. In Brussels, for example, the discussion led to the implementation of a solution which was second in the overall ranking.

Fourth, for decision-makers, MAMCA brings objective evaluation into otherwise 'fuzzy' co-creation and offers a structured way of ranking alternative solutions which can facilitate decision-making. Fifth, involving participants in evaluation may increase their knowledge of evaluation methods and thereby reduce the 'black box' feeling that traditional expert-led evaluation methods may evoke.

Two disadvantages of applying MAMCA to co-creation were found. First, the evaluation in MAMCA requires expert knowledge, time and effort that citizens or NGOs may not have. While involving stakeholders in the evaluation may reduce the 'black box' feeling, expert knowledge is still necessary to correctly assess the impact of the alternative solutions on the stakeholders' criteria. Furthermore, collecting criteria and weights from stakeholders requires a series of interviews or surveys with significant organizational efforts involved.

Second, deciding which alternative solution(s) will be implemented ideally happens during a consensus-making workshop attended by citizens and stakeholders. In Brussels, the evaluation results were published online, 
and a consensus-making workshop was organized, but not all stakeholders attended.

\subsection{CONCLUSION}

This chapter has shown how citizens and stakeholders participating in co-creation can be involved in the evaluation of co-designed solutions using Multi-Actor Multi-Criteria Analysis (MAMCA). Applying MAMCA in a co-creation process involves citizens and stakeholders in the evaluation of co-designed alternative solutions. The involvement of citizens in the evaluation of co-designed solutions to traffic safety problems in Brussels was found to have an overall positive impact on the co-creation process. Furthermore, MAMCA makes evaluation - which is traditionally a top-down and expert-led exercise - participatory. This approach fits well with the aims of citizen involvement and empowerment integral to co-creation.

Although co-creation and participatory evaluation have been researched individually, the intersection of these two topics is the main contribution of this chapter. The experiences of combining MAMCA and co-creation are promising, but adaptations should be made for their integration to work better in other contexts. Based on the experiences in Brussels, we make two recommendations:

1. The selection of alternative solutions that will be evaluated should be done openly, based on stakeholders' input and guidance of the evaluators.

2. Citizens should be divided into different stakeholder groups to integrate their diversity into the evaluation. Differences in views will become more salient in projects that are larger in scale and/or more complex.

\section{ACKNOWLEDGEMENTS}

The research described in this chapter was carried out in the LOOPER Learning Loops in the Public Realm project (www.looperproject.eu). The support of Brussels Capital Region - Innoviris (Belgium), Ministero dell'Istruzione dell'Università e della Ricerca (MIUR) (Italy), the Economic and Social Research Council (UK) and the European Union is gratefully acknowledged.

\section{REFERENCES}

Almeida, A.C.L. (2019). Multi actor multi criteria analysis (MAMCA) as a tool to build indicators and localize sustainable development goal 11 in Brazilian municipalities. Heliyon, 5(8). https://www.doi.org/10.1016/j.heliyon.2019.e02128. 
Arnstein, S. (1969). A ladder of citizen participation. Journal of the American Planning Association, 35(4), 216-224.

Bana E Costa, C.A. (2001). The use of multi-criteria decision analysis to support the search for less conflicting policy options in a multi-actor context: case study. Journal of Multi-Criteria Decision Analysis, 10(2), 111-125.

Boardman, A.E., Greenberg, D.H., Vining, A.R., and Weimer, D.L. (2018). Cost-Benefit Analysis: Concepts and Practice (5th edn). Cambridge: Cambridge University Press.

Booth, C., and Richardson, T. (2001). Placing the public in integrated transport planning. Transport Policy, 8(2), 141-149.

Brans, J.P., Vincke, P., and Mareschal, B. (1986). How to select and how to rank projects: The Promethee method. European Journal of Operational Research, 24(2), 228-238.

Dean, M. (2018). Assessing the applicability of participatory multi-criteria analysis (MCA) methodologies to the appraisal of mega transport infrastructure. Doctoral dissertation, University College London.

Dean, M., and Hickman, R. (2018). Comparing cost-benefit analysis and multi actor multi criteria analysis: the case of Blackpool and the South Fylde Line. In: M. Macharis and G. Baudry (eds), Decision-Making for Sustainable Transport and Mobility (pp. 100-119). Cheltenham, UK and Northampton, MA, USA: Edward Elgar Publishing.

Dodgson, J., Spackman, M., Pearman, A., and Philips, L. (2009). Multi-Criteria Analysis: A Manual. Department for Communities and Local Government. https:// www.gov.uk/government/publications/multi-criteria-analysis-manual-for-making -government-policy.

Gil, A., Calado, H., and Bentz, J. (2011). Public participation in municipal transport planning processes - the case of the sustainable mobility plan of Ponta Delgada, Azores, Portugal. Journal of Transport Geography, 19(6), 1309-1319.

Goepel, K.D. (2018). Implementation of an Online Software Tool for the Analytic Hierarchy Process (AHP-OS). International Journal of the Analytic Hierarchy Process, 10(3). https://www.doi.org/10.13033/ijahp.v10i3.590.

Harrison, S.R., and Qureshi, M.E. (2000). Choice of stakeholder groups and members in multicriteria decision models. Natural Resources Forum, 24(1), 11-19.

Healey, P. (1992). Planning through debate: the communicative turn in planning theory. Town Planning Review, 63(2), 143-162.

Holden, M. (2011). Public participation and local sustainability: questioning a common agenda in urban governance. International Journal of Urban and Regional Research, $35(2), 312-329$.

Kaza, N. (2006). Tyranny of the median and costly consent: a reflection on the justification for participatory urban planning processes. Planning Theory, 5(3), 255-270.

Larson, K.L., and Lach, D. (2008). Participants and non-participants of place-based groups: an assessment of attitudes and implications for public participation in water resource management. Journal of Environmental Management, 88(4), 817-830.

Macharis, C. (2007). Multi-criteria analysis as a tool to include stakeholders in project evaluation: the MAMCA method. In: E. Haezendonck (ed.), Transport Project Evaluation (pp. 115-131). Cheltenham, UK and Northampton, MA, USA: Edward Elgar Publishing.

Macharis, C., and Bernardini, A. (2015). Reviewing the use of multi-criteria decision analysis for the evaluation of transport projects: time for a multi-actor approach. Transport Policy, 37, 177-186. 
Macharis, C., De Witte, A., and Ampe, J. (2009). The multi-actor, multi-criteria analysis methodology (MAMCA) for the evaluation of transport projects: theory and practice. Journal of Advanced Transportation, 43(2), 183-202.

Macharis, C., De Witte, A., and Turcksin, L. (2010). The Multi-Actor Multi-Criteria Analysis (MAMCA) application in the Flemish long-term decision making process on mobility and logistics. Transport Policy, 17(5), 303-311.

Macharis, C., and Januarius, B. (2010). The multi-actor multi-criteria analysis (MAMCA) for the evaluation of difficult transport projects: the case of the Oosterweel connection. In 12th WCTR Lisbon, Portugal.

Macharis, C., Turcksin, L., and Lebeau, K. (2012). Multi actor multi criteria analysis (MAMCA) as a tool to support sustainable decisions: State of use. Decision Support Systems, 54(1), 610-620.

Marletto, G., and Mameli, F. (2012). A participative procedure to select indicators of policies for sustainable urban mobility. Outcomes of a national test. European Transport Research Review, 4(2), 79-89.

Mathie, A., and Greene, J.C. (1997). Stakeholder participation in evaluation: how important is diversity? Evaluation and Program Planning, 20(3), 279-285.

Muñuzuri, J., Onieva, L., Cortés, P., and Guadix, J. (2016). Stakeholder segmentation: different views inside the carriers group. Transportation Research Procedia, 12, 93-104.

Pappers, J., Keserü, I., and Macharis, C. (2020). Co-creation or Public Participation 2.0? An Assessment of Co-creation in Transport and Mobility Research. In: B. Müller and G. Meyer (eds), Towards User-Centric Transport in Europe 2: Enablers of Inclusive, Seamless and Sustainable Mobility (pp. 3-15). Cham: Springer International Publishing.

Plottu, B., and Plottu, E. (2009). Approaches to participation in evaluation: some conditions for implementation. Evaluation 15, 343-359. https://doi.org/10.1177/ 1356389009106357.

Schroeter, R., Scheel, O., Renn, O., and Schweizer, P.-J. (2016). Testing the value of public participation in Germany: theory, operationalization and a case study on the evaluation of participation. Energy Research and Social Science, 13, 116-125.

Smith, R.W. (1973). A theoretical basis for participatory planning. Policy Sciences, 4(3), 275-295.

Stagl, S. (2006). Multicriteria evaluation and public participation: the case of UK energy policy. Land Use Policy, 23(1), 53-62.

Te Boveldt, G. (2019). All aboard? A new evaluation approach for institutionally complex transport projects. Doctoral dissertation, Vrije Universiteit Brussel, Brussels.

Transplus (2003). Achieving sustainable transport and land use with integrated policies. http://www.isis-it.net/Transplus/TrDoc/T_inglese.pdf.

Turcksin, L., Macharis, C., Lebeau, K., Boureima, F., Van Mierlo, J., et al. (2011). A multi-actor multi-criteria framework to assess the stakeholder support for different biofuel options: the case of Belgium. Energy Policy, 39(1), 200-214.

Verlinde, S., and Macharis, C. (2016). Who is in favor of off-hour deliveries to Brussels supermarkets? Applying multi actor multi criteria analysis (MAMCA) to measure stakeholder support. Transportation Research Procedia, 12, 522-532.

World Health Organization (2018). Global Status Report on Road Safety 2018. World Health Organization. https://apps.who.int/iris/bitstream/handle/10665/276462/ 9789241565684-eng.pdf?ua $=1$. 